\title{
AS LIDERANÇAS NA ORGANIZAÇÃO EMPRESARIAL CONTEMPORÂNEA: UMA ABORDA- GEM DE RELAÇÃO INTERSUBJETIVA ENTRE O HOMEM E A ORGANIZAÇÃO DE TRABALHO
}

\author{
Márcia Oki Boin \\ Programa de Mestrado em Psicologia, Universidade Estadual Paulista - UNESP/Assis
}

RESUMO: Este artigo apresenta sumariamente o trabalho de pesquisa realizado em uma organização empresarial em transição, de pequeno para médio porte, que enfrenta com o seu crescimento, a necessidade de reorganizar a estrutura, os processos e principalmente as relações. Teve por objetivo o desvelamento da relação intersubjetiva estabelecida no confronto entre um grupo de lideranças e a organização de trabalho, buscando o acesso à realidade através da vivência desses indivíduos, como eles pensam a sua relação com o trabalho, produzem interpretações de sua situação, reagem, organizam-se e atuam sobre a dinâmica organizacional.

PALAVRAS-CHAVE: relação intersubjetiva; organização de trabalho; cultura organizacional; ressonância simbólica; subjetividade.

\section{THE LEADERSHIP IN THE CONTEMPORARY ENTERPRISE ORGANIZATION : A BOARDING OF INTERSUBJECTIVE RELATION BETWEEN THE MEN AND THE ORGANIZATION OF WORK}

ABSTRACT: This paper brings a summary of a research done in a business organization in transition from small to medium size facing with its growth the need to reorganize its structure, processes and mainly its relations. It aimed at unveiling the inter-subjective relation established in the comparison between a group of leaderships and the working organization. We sought access to reality through these individuals' life experiences, how they think their relation with work, interpret their situations, react, organize and act towards the organizational dynamics.

KEY WORDS: inter-subjective relation; working organization; organizational culture; symbolic resonance; subjectivity.

\section{INTRODUÇÃO}

O presente artigo apresenta sumariamente o trabalho de pesquisa realizado em uma organização empresarial. Tem como objetivo a busca da compreensão da relação intersubjetiva estabelecida no confronto entre o indivíduo, portador de uma história particular e singular e a organização de trabalho, caracterizada pela formação e evolução de sua cultura.

Segundo DEJOURS (1994), o enfoque na relação intersubjetiva abrange conceitualmente dois aspectos:

- privilegia a relação social em detrimento da relação técnica, meramente cognitiva e racional pressupondo que a relação com as pressões técnicas aparece fundamentalmente sujeita a um contexto subjetivo; a relação estabelecida com o

\footnotetext{
* Correspondência:

E-mail: boinman@hotmail.com
} 
processo de trabalho é sempre secundária e mediatizada pelas relações hierárquicas, conflituais, de reconhecimento, de luta e cooperação entre as pessoas;

- encontra-se sempre no centro da organização do trabalho sendo esta constantemente modificada e determinada pelas relações sociais e pelo movimento da integração humana que lhe dá sua forma concreta.

Assim, este trabalho se fundamenta no estudo da subjetividade nas organizações através de dois grandes eixos norteadores:

O primeiro eixo parte de uma visão antropológica da organização, sendo a mesma vista como um sistema cultural ou complexo coletivo constituído de representações mentais que ligam a instancia material (estruturas econômicas, sociais e técnicas, leis e normas e as vivências concretas) e a instância imaterial (subsistema simbólico constituído pelo universo das representações individuais e coletivas que dão sentido às ações), numa relação de estreita interdependência (AKTOUF, 1994).

O segundo eixo refere-se à abordagem do comportamento humano nas organizações, partindo do sujeito que trabalha e a relação do seu desejo face às atividades profissionais exercidas e a contribuição do seu trabalho para a construção equilibrada e integralizante do seu ser.

Nessa perspectiva, o homem é um ser pensante, um sujeito que reflete sua relação com o trabalho, produz interpretações de sua situação e atua sobre o processo, contribuindo para a construção e evolução das relações sociais estabelecidas. Desse modo, o vivenciado e as condutas são fundamentalmente organizadas pelo sentido que os sujeitos atribuem ao trabalho.

Portanto, as organizações enquanto estruturas não existem em si, são sempre habitadas, modeladas pelos homens e que, na sua ação fazem-nas viver, as esculpem e lhes dão sua significação.Não existem fronteiras entre o todo e as partes, uma vez que as partes são sempre constituídas e constituintes do todo e vice-versa.

ENRIQUEZ (1999), reportando-se a essa relação entre o social e o psíquico, assinala que o mais íntimo do ser humano nos leva ao mais essencial do social e que os problemas fundamentais da sociedade se inscrevem no corpo e no psiquismo. Esse movimento dialético pressupõe a unidade entre sujeito psíquico e sujeito social, como sujeito da história individual e do desejo inconsciente e como produtor e produto da história social e de suas transformações. Parte da concepção de que o sujeito se constitui na relação com outro sujeito através da relação intersubjetiva. Portanto, a subjetividade, suas manifestações e expressões são constituídas nas relações sociais.

Baseado na teoria analítica freudiana como referência, Enriquez parte da afirmação de que o pulsional faz parte do fundamento de cada sujeito e do fundamento da vida social. As características singulares do ser humano fazem dele um ser pulsional e um ser social e encontra-se constantemente dividido entre o reconhecimento de seu desejo e o desejo de reconhecimento.

"As pulsões farem parte diretamente do jogo de identificações, ou seja, todo conflito pulsional se inscreve fundamentalmente como um conflito identificatório, na medida em que todo ser humano está constantemente dividido entre o reconhecimento de seu desejo e o desejo de reconhecimento, as pulsões que o animam são obrigadas, para encontrar satisfaça, a voltar-se para a existência do outro... O desejo (qualquer que seja) para trilhar seu caminho, deve poder ser aceito pelo sujeito (e ser identificado pelos outros), que pode se identificar como sujeito desse desejo..." (ENRIQUEZ, 1999, p. 17)

Os fundamentos do trabalho nasceram da leitura da revisão das obras de FREUD (1996) buscadas por ENRIQUEZ (1999) como referência essencial na análise dos fenômenos sociais, especificamente do vínculo social. Estes estudos nos apontam os fundamentos do social e o advento da cultura, a natureza da civilização e o seu desenvolvimento no decorrer dos tempos e os mecanismos do funcionamento do social, tratando dos elementos fundamentais ao funcionamento dos grupos e das organizações.

Citaremos alguns dos eixos principais colocados pelo autor que fundamentam a análise dos fenômenos sociais:

- a ligação entre a realidade psíquica e a realidade histórica: em Totem e Tabu (FREUD, 1996 - vol. XIII) inaugura sua teoria do fundamento do social e da cultura demonstrando que a civilização somente se inicia com o crime; portanto, o parricídio é indispensável à criação da cultura, pois ele nos introduz no mundo da culpabilização, da renúncia, da necessidade de referência a uma lei transcendente que se manifestará na organização social, nas restrições morais e na religião.

A civilização nasce com e pela repressão. Não pode existir corpo social (instituições, organizações) sem a instauração de um sistema de repressão coletivo. Para se constituir, uma sociedade deve impedir a realização não mediatizada da satisfação da pulsão sexual e do desejo. 
- o eterno jogo entre a pulsão de vida e a pulsão de morte: o sistema dual das pulsões governa todas as manifestações da vida. A pulsão de vida, representante das exigências da libido, agrega, une e permite a ligação entre os seres. A pulsão sexual originária, inibida quanto ao objetivo, sublimada e manifestada através de sentimentos de amizade, ternura, solidariedade é indispensável para a criação e manutenção de agrupamentos sociais. Por outro lado, a pulsão de morte separa, desagrega, tende ao retorno ao estado inorgânico; como pulsão de destruição pode ser voltada para o exterior ou interior do indivíduo.

- a civilização como renúncia á satisfação das pulsões: em Psicologia e a Análise do Ego (FREUD, 1996 - vol. XVIII), Freud concebe o nascimento do grupo, o papel do pai para continudidade da sua sobrevivência e a necessidade do grupo ser portador de um projeto comum para se constituir enquanto tal. A partir da análise da formação dos agrupamentos humanos considera que somente o amor dessexualizado é favorável á formação coletiva. Portanto, a civilização é desde o princípio contra o Eros, que pode assumir a forma de perturbador, do imprevisto, da paixão e da individualização.

Desse modo, as organizações para se manter tendem a canalizar a pulsão de vida para unicamente o trabalho produtivo e teme, que os sentimentos positivos e de afetividade propiciem o surgimento de condutas irracionais e sem controle.

\section{A PESQUISA}

A empresa pesquisada encontra-se em fase de transição de pequeno para médio porte, tendo como base a sua faixa de faturamento. Sua estrutura tem sido constantemente reordenada para atender ao seu crescimento em função das demandas do mercado.

Como qualquer organização empresarial da atualidade, inserida em um contexto social e econômico em constante mudança, os conflitos são constantes e quase que inevitáveis na tentativa contínua de responder às exigências do mercado globalizado. As situações de mudanças repercutem diretamente no reordenamento dos processos, das relações e dos recursos existentes e exigem, para se efetivarem, mudanças na gestão empresarial.

Focalizamos um grupo representativo das lideranças da empresa, pertencentes ao nível hierárquico intermediário, representado pelos coordenadores de setores que, na estrutura organizacional situam-se entre o nível estratégico (diretoria e gerências de áreas) e o nível técnico-operacional (analistas e auxiliares).

Portanto, os sujeitos constituem o componente tático da organização, responsável pela articulação interna entre os níveis estratégico e operacional. A escolha desse segmento deveu-se ao fato dessas pessoas ocuparem uma posição dentro da estrutura onde se concentra ou catalisa as maiores pressões no trabalho, pois sofre diretamente os impactos das propostas de mudanças que recebe das decisões tomadas pelo comando da organização e tem como responsabilidade maior transformar e traduzir logicamente essas decisões em planos e programas de ação para suas equipes subordinadas.

Foram selecionados como sujeitos da pesquisa nove lideranças, coordenadores de setores administrativos, de ambos os sexos, tendo como único critério de escolha o tempo mínimo de três anos de vivência dentro da empresa.

Os relatos dos sujeitos foram obtidos através da técnica de entrevistas individuais. Optamos em realizar uma entrevista semi-estruturada, tendo como norteador um roteiro guia, com o intuito de permitir ao pesquisador conduzir a entrevista e estimular a produção do discurso em função de alguns temas que caracterizam:

- a gestão vigente (caracterização do comando da empresa de ontem e de hoje; caracterização da sua gestão enquanto chefia intermediária na condução de suas equipes; caracterização da atuação de sua equipe mediante a sua forma de administrar);

- sua história passada (condições de escolha da profissão, focalizando as relações parentais na infância; vivência lúdica; adolescência; condições de escolha da profissão);

- sua vivência como profissional (imagem que tem da profissão em relação às funções que exerce; condições oferecidas pela organização do trabalho: espaço de concepção/execução, autonomia e criatividade; reconhecimento social obtido pela hierarquia e pelos pares).

Buscamos inicialmente a compreensão do universo das lideranças partindo da compreensão das exigências internas e externas à empresa que condicionam a sua atuação. Através da revisão do trajeto histórico das organizações de trabalho podemos perceber como as mesmas vêm evoluindo de uma concepção mecanicista e simplificadora para outra, sistêmica, integradora e complexa, demonstrando como as transformações do ambiente geral ou macroambiente afetam diretamente seu ambiente interno ou microambiente. 
Vários modelos de gestão e metodologias de transformação organizacional foram criados, sempre na tentativa de melhorar a produtividade, a qualidade e a rentabilidade das empresas. Embora muitas das inovações sejam apenas reedições das idéias existentes, demonstrando com isso uma grande dificuldade das organizações em romper com o modelo mecanicista, se analisadas em conjunto constituem uma abordagem mais integrada e humanizada.

Podemos observar que o momento em que o conceito de cultura da empresa ou gestão pela cultura começa a ganhar força abre-se aí um espaço, forçando o paradigma clássico a introduzir no mundo racional da organização algo que sempre recusara a admitir como elemento constitutivo do seu universo, a dimensão subjetiva.

Dentre as várias vertentes de estudo sobre a cultura organizacional, o presente trabalho parte do referencial dos estudos sobre a organização enquanto unidade sociocultural que priorizam a dimensão psicológica como fundamental para se adquirir uma compreensão mais aprimorada da empresa enquanto sistema social.

AKTOUF (1994) faz uma severa crítica aos estudiosos da corrente predominante do management norte-americano que defendem uma visão funcionalista e instrumental da cultura, baseada no pressuposto de que a empresa pode ser ou ter uma cultura e que esta poder ser ou não eficiente, podendo ser diagnosticada para ser transformada e manipulada à revelia pelos dirigentes.

Argumenta que embora a cultura seja construída por meio da interação e que os dirigentes tem um papel importante no estabelecimento das condições dessa interação, não concorda com a firmação de que a cultura possa ser diferente da realidade vivida, espontânea e subjetiva dos indivíduos, diferente da relação desses indivíduos com suas condições de existência, para ser alguma coisa que pode ser mudada.

Portanto, a cultura é algo que está profundamente inscrito nas estruturas sociais, na história, no inconsciente, na experiência vivida e no vir a ser coletivo.

Através da visão da organização enquanto unidade sociocultural é que procedemos a análise da relação intersubjetiva das lideranças com a organização do trabalho. Enfocamos especificamente a articulação entre o tema da cultura organizacional e a cultura brasileira, em busca da identificação de traços culturais brasileiros que impactam na gestão empresarial, conferindo à organização do trabalho características peculiares ao seu funcionamento.

Acreditamos que é justamente nesse impacto dos traços culturais brasileiros na gestão empresarial em confronto com os modelos importados de gestão que se configura uma situação real e de pressão no trabalho.

Passaremos em seguida a apresentação sumária do referencial teórico metodológico que embasaram o levantamento, o ordenamento e a análise dos dados da pesquisa, através de duas vertentes principais: o contexto sociocultural da organização e a história individual dos sujeitos.

\section{O CONTEXTO SÓCIO CULTURAL DA ORGANIZAÇÃO}

Com a globalização da economia e conseqüente internalização dos negócios, os debates acerca da influência da cultura nacional na teoria e prática de gestão começam a se intensificar e a idéia de uma prática administrativa geral e universal começa a cair por terra.

Salienta CALDAS e WOOD JR (1999) que, os trabalhos sobre cultura organizacional no Brasil têm sido muito influenciados pela corrente gerencialista americana, levando os dirigentes envolvidos em processos de mudança organizacional a importarem modelos de gestão e de metodologias de transformação organizacional como forma de enfrentar os desafios trazidos pela concorrência e a abertura de mercados em escala mundial. As empresas locais têm importado tecnologia gerencial provocando com isso um afastamento entre discurso e prática gerencial, justamente pela tentativa de aplicação dessa tecnologia em um contexto culturalmente diverso do original.

Para compreendermos algumas das características atuais de gestão das organizações no Brasil, necessitamos proceder à análise dos traços originais da cultura brasileira. Essa análise nos remete aos principais grupos étnicos que compuseram a nossa cultura e a conseqüente miscigenação cultural, a forma de colonização e as implicações da economia escravocrata, latifundiária e da monocultura na formação dessa cultura.

A retomada da história da colonização no Brasil nos revela as condições nas quais a sociedade brasileira esteve historicamente imersa e possibilitam a compreensão da nação que hoje temos e do povo que hoje somos, além de que nos oferecem o substrato de como se construiu o nosso imaginário social.

Demonstra-nos a influência do colonizador português na cultura brasileira, temperada e miscigenada pelo índio e depois pelo negro e após alguns séculos pelo povo europeu e asiático, levando-nos a refletir sobre a herança cultural determinada pelo processo histórico de colonização de 500 anos que influenciou na constituição dos indivíduos que 
compõem a sociedade brasileira hoje.

BORGES DE FREITAS (in Motta e Caldas, 1997) sumarizam alguns traços que são mais influentes no âmbito organizacional como: a hierarquia; o personalismo; a ambigüidade; a plasticidade e permeabilidade e o aventureiro.

Esses traços culturais foram abordados por BARROS e PRATES (1996) em pesquisas que visaram compreender como e quando eles se manifestam no contexto organizacional, através da articulação entre quatro subsistemas interdependentes: entre líderes e liderados e entre institucional e pessoal, caracterizado pela figura abaixo:

\section{Lideres}

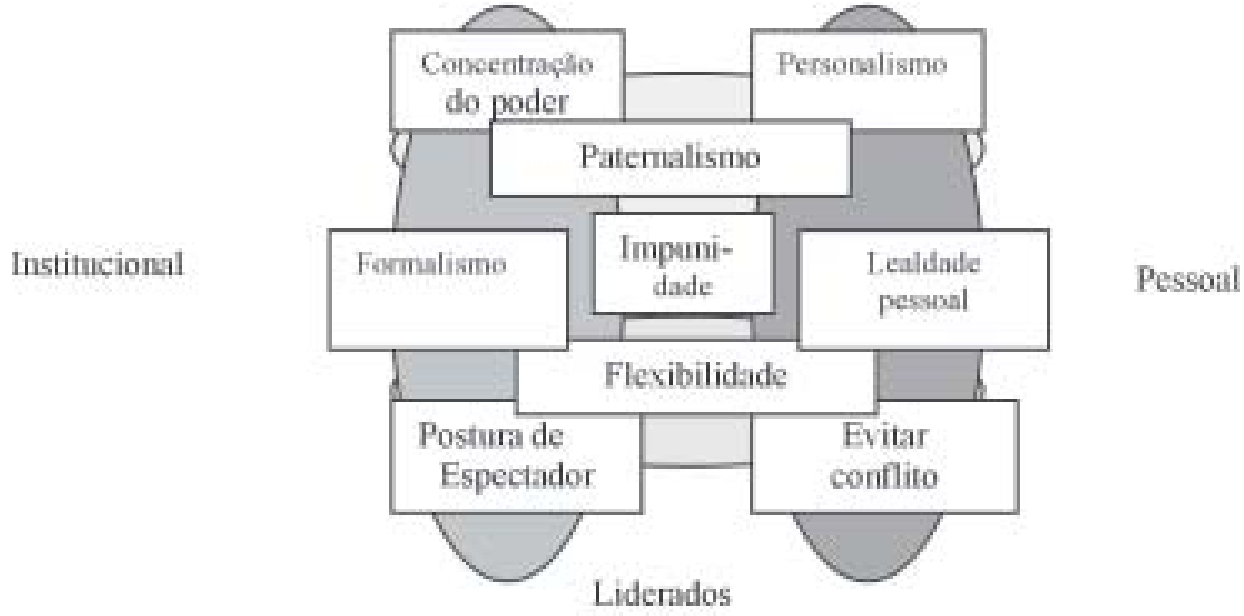

(BARROS e PRATES, 1996, p.31)

Tendo por base os estudos da visão integrada do sistema de ação cultural brasileiro é que procedemos a análise dos dados. Consideramos como referência os seguintes componentes de gestão: o processo decisório e a formulação de estratégias empresariais; o processo de liderança; o processo de coesão organizacional; o processo de inovação e mudança e o processo de motivação.

A análise dos relatos dos sujeitos demonstrou os seguintes resultados:

- concentração de poder no topo da pirâmide hierárquica;

- personalismo como traço atuante da diretoria que define os rumos estratégicos da organização individualmente;

- manutenção do poder pela preservação das informações, pois a faceta do personalismo é que todos saibam quem manda na empresa;

- gestão centralizadora da diretoria e postura de espectador pelos gerentes que sentem-se tolhidos em suas ações pela falta de autonomia e que procuram evitar o conflito, o confronto e a desigualdade, na tentativa de fazer valer suas idéias e pontos de vista divergentes;

- aversão ao risco e baixa tolerância ao erro, não incentivando a todos a propor melhorias;

- no processo de formulação de estratégias adota uma posição defensiva perante as exigências e influências do meio externo;

- falta de um planejamento integrado que norteie as ações e diminua a chance do risco e da incerteza, perpetuando a cultura de "apagar o fogo".

- aversão ao trabalho disciplinado e metódico justamente por priorizar as ações imediatas de caráter reativo e metódico;

- gestão caracterizada por atitudes paternalistas aliadas ao "jeitinho brasileiro" que busca o favorecimento de alguns em detrimento de uma norma ou procedimento estabelecido;

- distância entre o discurso e a prática; 
- legitimação do poder do líder ocorre pela lealdade pessoal reforçada pela hierarquia;

- hierarquização das relações onde as ações são movidas por quem as solicitou e não propriamente pelo conteúdo real da solicitação;

- impunidade e ausência de premiação e reconhecimento dos eficientes;

- ausência de feedback e não reconhecimento do trabalho executado;

- morosidade de tomada de decisões e definições do nível estratégico.

A análise dos principais componentes de gestão que caracterizam o contexto sociocultural da organização em questão nos levou a uma visão geral de como se processa a organização de trabalho desta empresa, onde a divisão de tarefas e o modo operatório prescrito (segmentação dos processos através da setorização) e a divisão entre os homens imposta pela repartição das responsabilidades pela hierarquia e pelo controle constituem muitas vezes uma fonte de pressão, sofrimento e mal-estar de seus funcionários.

Essa constatação demonstra em primeiro plano uma dificuldade das empresas em romper com os paradigmas da Administração Científica que acabam sobrevivendo, apesar das situações de mudanças impostas pelo processo de modernização.

Embora a dinâmica do ambiente externo exija das organizações um processo contínuo de reorganização como forma de mantê-las competitivas, no nível das pessoas o pleno entendimento, aceitação e interiorização dessas mudanças não ocorrem no mesmo ritmo e facilidade, criando uma desintonia entre discurso e prática.

As evoluções do presente estágio para um sentido de futuro em longo prazo, em busca de melhor alinhamento dos elementos culturais, econômicos e sociais, dependerão com certeza, em primeiro lugar de um propósito priorizado, disciplinado e persistente da diretoria da empresa, que possui enfim plena autonomia e poder para buscar um método de gestão que propicie um ambiente mais saudável e participativo.

\section{A HISTÓRIA PASSADA E BUSCA DO SENTIDO DO TRABALHO}

Tendo em vista o objetivo da pesquisa, o de analisar a relação intersubjetiva estabelecida entre os sujeitos e a organização do trabalho e, uma vez caracterizado o contexto sociocultural, passaremos ao entendimento dos sujeitos envolvidos nessa relação, priorizando especificamente o processo de ressonância simbólica que articula o teatro privado da história singular dos sujeitos ao teatro atual e público do trabalho.

A ressonância simbólica ocorre quando há uma compatibilização entre as representações simbólicas do sujeito, seus investimentos pulsionais e a realidade do trabalho. Para ocorrer esse processo é necessário que a tarefa tenha um sentido para o sujeito com base em sua história de vida.

Consideramos como referencial de análise os aspectos apontados por Dejours como fundamentais para verificação das condições do estabelecimento da ressonância simbólica entre o passado e o presente, quais sejam: a escolha da profissão, a relação entre concepção e execução na administração de suas tarefas e o reconhecimento social pelo desenvolvimento profissional.

a) a escolha da profissão

Verificamos pela análise dos dados que, embora as condições sócio-econômicas da família tenham influenciado o processo de escolha profissional da maioria dos sujeitos entrevistados, essa questão por si só não possui relação direta com a maior ou menor satisfação do sujeito no exercício de sua carreira. Portanto, a questão que se coloca é se o trabalho atual (desviado ou não de seu projeto inicial) oferece condições de satisfação sublimatória, ou seja, um lugar onde o sujeito possa transferir sua energia pulsional que inicialmente foi dirigida para as figuras parentais com objetivo de satisfação imediata, para as relações sociais com satisfação mais altruísta.

Portanto, o fator fundamental encontra-se nas relações parentais estabelecidas dentro da dinâmica familiar que possibilitaram ou não a aquisição de recursos internos para lidar com situações adversas encontradas na vida profissional e a capacidade de dar um rumo à vida produtiva. Assim sendo, as dificuldades vivenciadas nas relações infantis com os pais passam a ser impeditivas para o sujeito vivenciar o processo de ressonância na relação com o trabalho.

Desse modo, observamos uma relação estreita entre relações parentais e desempenho profissional. Os sujeitos que tiveram na sua biografia uma falta ou carência de contato, de presença das figuras parentais (pai ou mãe), apresentam dificuldades em sua gestão enquanto chefias, principalmente no que diz respeito à postura que devem adotar na condução 
de sua equipe variando do extremo autoritarismo à anulação da posição de liderança caracterizada pela omissão na orientação e condução do trabalho de suas equipes.

Por outro lado, os sujeitos que possuem uma imagem forte da figura parental, tendem a mobilizar nas relações de trabalho os aspectos mais fortes da personalidade materna ou paterna que por identificação foram interiorizados como: ser justo com a equipe, ser companheiro e valorizar a todos, ser autoritário e cobrador quando necessário, ser batalhadora, não ser submissa para ser competente, ser responsável como a filha mais velha, etc...

b) a atividade de concepção X atividade de execução: o uso da inteligência astuciosa

Outro recurso utilizado pelo indivíduo para transformar o sofrimento em prazer mediante a delimitação do seu espaço pelas imposições da organização do trabalho, seria o uso da inteligência conceituada por Dejours como astuciosa, pois pressupõe, sobretudo uma constante ruptura com as normas e regras, sendo fundamentalmente transgressiva.

A utilização da inteligência astuciosa tem sua raiz nas percepções e na intuição sensível do indivíduo que, em situações onde requer um ajustamento das relações entre as prescrições das tarefas e obstáculos impostos pela organização do trabalho, origina-se da experiência real do indivíduo e da sua concepção sobre a atividade.

A busca da união entre concepção e execução da atividade torna-se fundamental para que o indivíduo consiga transpor o hiato existente entre a organização prescrita e a organização real no confronto entre o que é imposto pela organização do trabalho e as necessidades psíquicas desse indivíduo.

A investigação sobre essa questão demonstrou que existem espaços e liberdade para criar e propor no nível das idéias e no reduto do espaço privado. Porém, para estender as propostas ao domínio público as lideranças necessitam de aprovação do nível estratégico e a dificuldade está justamente na morosidade no retorno das propostas que são encaminhadas, devido à falta de integração do grupo gerencial em discutir conjuntamente a implantação de mudanças e centralização de poder para aprovação final pela diretoria.

Desse modo, quando esse processo de decisão finalmente se concretiza, a desarticulação e falta de coesão do grupo gerencial não leva a uma atitude de comprometimento e retaguarda com seus setores.

Pela falta de integração dos setores em torno de metas comuns da empresa como um todo, a implantação de propostas passa por caminhos tortuosos e ineficazes.

c) o reconhecimento da competência do indivíduo pelos pares e hierarquia:

Outro fator considerado pela Psicodinâmica do Trabalho para o estabelecimento da ressonância simbólica referese à validação positiva de sua escolha profissional, ou seja, o reconhecimento do seu trabalho pela hierarquia e pelos pares, pois submetendo o trabalho à crítica, o sujeito espera em troca ser reconhecido.

Segundo FREUD (1996, vol. XVIII), a relação dialeticamente construída entre indivíduo e meio social requer a existência de um outro, pois é na relação com o outro que o ego se constrói. É a relação que permite a construção dos seres e a constituição do psiquismo.

O reconhecimento é, portanto, a retribuição fundamental da sublimação e contribui para a construção da identidade. Para conseguir o reconhecimento o sujeito mobiliza-se subjetivamente, ou seja, utiliza-se da sua inteligência e dos recursos disponíveis fazendo uso de sua personalidade e inteligência para se contrapor a uma racionalidade subjetiva específica gerada na situação de trabalho.

A contribuição à organização de trabalho tem como retorno a retribuição simbólica que se dá pelo reconhecimento.Dessa forma, a organização do trabalho é um compromisso resultante da negociação social simultânea entre os pares e os diferentes níveis hierárquicos.

O sofrimento e as defesas se instalam no momento em que os trabalhadores não têm a possibilidade de utilizar o processo de mobilização subjetiva ou sentir prazer resultante do investimento sublimatório, seja por restrições de sua estrutura de personalidade seja pelas imposições do modelo de organização do trabalho.

Os resultados da pesquisa demonstraram que o modelo vigente de organização do trabalho não favorece o acolhimento de novas propostas (que possuem maior chance de serem reconhecidas) devido às características de gestão já citadas.

A dificuldade da atitude do reconhecimento deve-se à rigidez da organização do trabalho que se mantém pelo controle da hierarquia e o exercício rígido da autoridade. A centralização do poder no topo da organização e as atitudes paternalistas decorrentes aparecem na fala dos sujeitos quando dizem que se sentem reconhecidos pela empresa por terem chegado ao cargo de chefia (promoção) e por terem sido encaminhados para treinamento (especialização), duas situações 
que na época eram determinadas somente pela direção.

Portanto, sendo o reconhecimento a retribuição fundamental da sublimação, podemos dizer que na empresa pesquisada o entrave ao jogo da sublimação não resulta tanto da incapacidade psíquica do sujeito quanto da ausência das condições organizacionais para o estabelecimento da ressonância simbólica.

$\mathrm{Na}$ impossibilidade de elaborar no ambiente de trabalho essa condição favorável, os sujeitos não conseguem beneficiar-se do trabalho para dominar seu sofrimento e transformá-lo em criatividade. Desse modo, tanto as condições pessoais de escolha da profissão quanto as condições reais de exercê-la tornam-se fundamentais para a saúde mental e somática do trabalhador.

\section{CONSIDERAÇÕES FINAIS}

A pesquisa nos revelou dados significativos que caracterizam o ambiente sociocultural atual da empresa que permanecem com o passar dos anos apesar do processo de modernidade exigido pelo ambiente externo competitivo.

A análise dos traços da cultura brasileira influenciando o modo de gestão demonstrou que possuímos enquanto povo, raízes históricas que influenciam nossas relações no âmbito pessoal e público e que, a partir delas é que poderemos germinar e criar um estilo próprio de administrar.

Nessa perspectiva, a importação ou adoção de tecnologias de gestão inovadoras negando nossas características culturais está fadada ao insucesso, aumentando a distancia entre discurso e a prática.

Desse modo, torna-se necessário recriarmos um processo para revigorar o estilo brasileiro de administrar, utilizando principalmente da nossa capacidade de criatividade e adaptabilidade a novas situações (BARROS e PRATES, 1996). Outro aspecto favorecedor de nossa cultura diz respeito a nossa capacidade de estabelecer relações pessoais e praticar a lealdade pessoal favorecendo à gestão brasileira a agilização das informações, a consolidação de alianças e comprometimento em torno de objetivos comuns e a humanização das relações internas e externas.

É preciso, no entanto, que os traços naturais de flexibilidade e lealdade prevaleçam sobre os traços do paternalismo e do formalismo e que a autoridade maior e concentradora de poder promova um outro tipo de relacionamento, baseado na interdependência entre líderes e liderados.

Cabe aos líderes, portanto, deixar de infantilizar os liderados e acreditar mais na capacidade deles e cabe aos liderados saírem da postura de transferência de responsabilidades para cima e assumir um papel mais ativo dentro de seu grupo de relações.

É fundamental, para que as mudanças evolutivas ocorram, que a autoridade central estimule o risco compartilhado e a sua contrapartida que é o reconhecimento compartilhado. As lideranças, desde o nível estratégico, deverão assumir uma atitude educativa, de forma a fazer o seu grupo crescer através de maior participação e envolvimento, orientando-o continuamente quanto aos rumos a serem tomados e favorecendo a abertura de caminhos dentro da organização.

A investigação do contexto sociocultural levou-nos a caracterização de como se processa dinamicamente a organização do trabalho da empresa, enriquecendo o universo do objeto da pesquisa que é a busca da relação intersubjetiva dos atores implicados nesse contexto.

A Psicodinâmica do Trabalho de Dejours possibilitou verificar a relação entre homem-trabalho, as condições de ressonância simbólica entre as experiências passadas e expectativas atuais e a situação de trabalho.

Assim, constatamos que a organização do trabalho na sua dinâmica de funcionamento não favorece às lideranças a possibilidade de reordenar o seu modo operatório, uma vez que para implantar novas propostas necessita da aprovação do comando estratégico da empresa. Vimos que em uma estrutura onde o comando e o poder decisório continuam centralizados no topo da cadeia hierárquica, torna-se difícil viabilizar qualquer proposta de inovação que venha dos extratos hierárquicos inferiores.

Nesse ambiente onde prevalece a centralização de poder, a hierarquia, a separação e o distanciamento das pessoas, a atitude do reconhecimento social não encontra espaço, uma vez que o reconhecimento é o resultado do risco de propostas inovadoras.

Considerando que o contexto organizacional atual não favorece as condições reais dos indivíduos exercerem a profissão criando entraves ao investimento e ao jogo sublimatório, torna-se necessário a criação de uma espaço público da palavra com o intuito de favorecer a busca do sentido do trabalho através da discussão e negociação sobre a organização real do trabalho e a conscientização do sofrimento.

O espaço coletivo de discussão favorecerá o grupo de lideranças intermediárias a externar seus conflitos e aflições 
e administrá-los coletivamente, fortalecendo os laços de confiança e solidariedade criados pela identificação dos sentimentos vivenciados no cotidiano.

Porém, é fundamental que os resultados da pesquisa cheguem ao comando da organização para que, através da conscientização das dificuldades apontadas pelas chefias intermediárias e sua repercussão na produtividade e qualidade, possam encontrar caminhos que promovam maior satisfação e sentido na relação homem-trabalho.

\section{REFERÊNCIAS BIBLIOGRÁFICAS}

AKTOUF, O . (1994) - O Simbolismo e a Cultura de Empresa: dos abusos conceituais às lições empíricas . In: CHANLAT, J.F.- O Indivíduo na Organização - dimensões esquecidas. Vol. II. São Paulo: Atlas.

AZEVEDO, F.(1964) - A Cultura Brasileira: introdução ao estudo da cultura no Brasil. $4^{a}$ edição. São Paulo: Melhoramentos.

BARBOSA, L. (1992) - O Jeitinho Brasileiro. Rio de Janeiro: Campus.

BARROS, B.T. e PRATES, M. S. (1996) - O Estilo Brasileiro de Administrar. São Paulo: Atlas.

BOSI, A. (org.) (1987) - Cultura Brasileira: temas e situações. Rio de Janeiro: Ática.

CALDAS, M.P. e WOOD JR. T.(1999) - Transformação e Realidade Organizacional : uma perspectiva brasileira. São Paulo: Atlas.

CALLIGARIS, C. (1997) - Hello Brasil! . São Paulo : Escuta.

CHANLAT, J.F. (1993) - Por uma Antropologia da Condição Humana nas Organizações. In: CHANLAT, J.F.(coord.)O Indivíduo na Organização dimensões esquecidas. Volume I.São Paulo: Atlas.

CHIAVENATO, I. (1999b) - Gestão de Pessoas ; o novo papel dos recursos humanos nas organizações. Rio de Janeiro: Campus.

DaMATTA, R. (1997)- Carnavais, Malandros e Heróis. Rio de Janeiro: Rocco.

DaMATTA, R. (1998) - O que faz o brasil, Brasil ?. Rio de Janeiro: Rocco.

DAVEL, E. e VASCONCELOS, J. (org.) (1995) - “Recursos” Humanos e Subjetividade. Petrópolis, RJ: Vozes.

DEJOURS, C. (1992) - A Loucura do Trabalho : estudo de psicopatologia do Trabalho. São Paulo: Cortez-Oboré.

DEJOURS, C. (1993) - Uma Nova Visão do Sofrimento Humano nas Organizações. In: CHANLAT, J.F. - O Indivíduo na Organização: dimensões esquecidas .Volume I. São Paulo: Atlas.

DEJOURS, C. (1997) - O Fator Humano. Rio de Janeiro: Fundação Getúlio Vargas.

DEJOURS, C. (1999) - A Banalização da Injustiça Social. Rio de Janeiro: Fundação Getúlio Vargas.

DEJOURS, C. (1991) - Repressão e Subversão em Psicossomática. Pesquisas psicanalíticas sobre o Corpo. Rio de Janeiro: Zahar.

DEJOURS, C., ABDOUCHELI, E., JAYET, C. (1994) - Psicodinâmica do Trabalho. São Paulo: Atlas. 
ENRIQUEZ, E. (1997) - A Organização em Análise. RJ: Vozes.

ENRIQUEZ, E. (1999) - Da Horda ao Estado. Psicanálise do Vínculo Social. São Paulo: Zahar.

FLEURY, M.T.L.e FISHER, R.M. (org.) (1989) - Cultura e Poder nas Organizações. São Paulo: Atlas.

FLEURY, M.T.M. (1996) - O desvendar a cultura de uma organização- uma discussão metodológica. In : FISHER, R.M. e FLEURY, M.T.M. (coord.) - Cultura e Poder nas Organizações. São Paulo: Atlas.

FREITAS, B. (1997) - Traços brasileiros para uma análise organizacional. In : MOTTA, F.C.P. e CALDAS, M.P. - Cultura Organizacional e Cultura Brasileira. São Paulo : Atlas.

FREITAS, M. E. (1989)- Cultura Organizacional: grandes temas em debate. Dissertação de Mestrado. São Paulo: FGV/ESESP.

FREUD, S. (1996) - Obras Completas de Sigmund Freud. Rio de Janeiro: Imago.

O mal-estar na Civilização. Vol.XXI, pg:75-282.

Psicologia de Grupo e Análise do Ego. Vol.XVIII, pg.89-182.

Totem e Tabu . Vol.XIII, pg. 21-162.

Leonardo da Vinci e uma lembrança de sua infância. Vol.XI, pg.67-142.

Moisés e o Monoteísmo. Vol.XXIII, pg.19-156.

O Futuro de uma Ilusão. Vol.XXI, pg.13-74.

GAY, P. (1989) - Do Divã para a Cultura. In: Freud para Historiadores. Rio de Janeiro: Paz e Terra.

HOLANDA, S.B. (1995) - Raízes do Brasil. Rio de Janeiro: José Olympio.

KUSNETZOFF, J.C. (1982) - Introdução à Psicopatologia Psicanalítica. Rio de Janeiro: Nova Fronteira.

LAPIERRE, L. (1995) - Imaginário e Liderança. São Paulo: Atlas .

LOPES, A e RETO, L. (1990) - Identidade da Empresa e Gestão pela Cultura. Lisboa: Sílabo.

MALVEZZI, S. (1992) - Psicologia Organizacional e Recursos Humanos: Tendências e Perspectivas. In : Cadernos CRP-06. $2^{\circ}$ Encontro de Psicologia e Trabalho. Setembro de 1992.

MALVEZZI, S. (1999) - Do Taylorismo ao Comportamentalismo - 90 anos de Desenvolvimento de Recursos Humanos . In : BOOG, G. G. - Manual de Treinamento e Desenvolvimento. São Paulo : Makron Books.

MINAYO, M.C.S. (2000) - O Desafio do Conhecimento. Pesquisa Qualitativa de Saúde. São Paulo: Hucitec e Rio de Janeiro: Abrasco.

MOTTA, F.C.P. e CALDAS, M.P.(1997) - Cultura Organizacional e Cultura Brasileira. São Paulo: Atlas. 
PAGÈS, M., BONETTTI, M. , GAULEJAC, V., DESCENDRE, D.(1993) - O Poder das Organizações. São Paulo: Atlas.

RIBEIRO, D. (1995) - O povo brasileiro: a formação e o sentido do Brasil. São Paulo: Companhia Brasileira das Letras .

SELIGMANN-SILVA, E. (1994) - Desgaste Mental no Trabalho Dominado. Rio de Janeiro: Cortez.

WOOD, JR. T. (coord.) (1995) - Mudança Organizacional. São Paulo: Atlas. 
Márcia Oki Boin

56 Colloquium Humanarum, Presidente Prudente, v.2, n.1, p. 45 - 56, jan.jun., 2004 